\title{
Determining the Role of English Language Competence in Influencing the Public Speaking Anxiety of International Post Graduate Students at the University of Utara, Malaysia
}

\author{
Ahmed Aiyad Gaibani \\ College of Arts and Sciences, Universiti Utara Malaysia, Sintok 06010, Kedah, Malaysia \\ E-mail: Dr.ahmed.gaibani@gmail.com \\ Current work-place: the Libyan university of Omar Al-Mukhtar, college of English \\ Language studies
}

Doi:10.5296/ijld.v4i2.4419 URL: http://dx.doi.org/10.5296/ijld.v4i2.4419

\begin{abstract}
This study investigates the roles of English language competence in influencing public speaking anxiety among the post graduate students of intensive English language program of the University Utara, Malaysia. A questionnaire survey was administered to a sample of 108 post graduate students of the intensive English language program to indicate their personal responses. Technique of correlation was further applied to the data collected to determine the relationship between English language competence and public speaking anxiety; however, the result revealed that English language competence has a significant negative effect on public speaking anxiety. Therefore, it is recommends that to overcome or lessen the anxiety faced by the students, the students need to identify their feelings about their speaking anxiety associated with English language, and on the path of lectures, students should be advised to engage in speaking practice out loud either lonely or with other colleagues as this has the tendency of increasing their efficiency level of speaking English language.
\end{abstract}

Key words: Anxiety, Public Speaking Anxiety, English Language Competence, Post Graduate Students

\subsection{Introduction}

Public speaking anxiety appears to be very rampant among students be it college or university students. This anxiety is particularly pronounced among the intensive postgraduate English language students of the university. For example, about 20 to 85 percent of intensive postgraduate English language students experience considerable anxiety anytime they have to speak in public (Katz, 2000; Hamilton, 2008). Some among these students are of the feeling that they perform better in public speaking if they had little nervousness before they started their public speaking while other students feel the impact of the anxiety even more to the extent that it affects their ability to compose themselves and perform better in public speaking. Consequent upon the adverse effect of the public speaking anxiety is the avoidance of intensive English language class by some of these affected students since they believe that they would have to participate in oral presentation or group discussion. Those who do not avoid the class may decide not to speak in the class or even relate with their colleagues whom they would have liked to know. Some of these students who are very anxious of public speaking in the class could tend not to participate in any interview, oral proposal defense or even attend social events. 
An anxiety could sometimes be likened to phobia. This has to do with a fear that is not in conformity with danger. In a situation where nervousness of public speaking is so much that it tampers with one's life or with what one wants to do, then one may have social phobia. Public speaking anxiety is one particular type of this social phobia. Observations have been made about the post graduate students of intensive English language. Some of them experiencing public speaking anxiety have shown their expressions that they are worried of being embarrassed anytime they speak in public. They are concerned of making mistake and thus not being judged attractively to the extent that they may look stupid before their fellow students. Some among them are of the opinion that they get upset because of their feeling that all attentions are placed on them and that what they are about to speak on may not be of interest to the audience. This fear of unfavorable assessment by the audience likely aggravates their public speaking anxiety.

Most of the students facing public speaking anxiety often believe that their group discussion, oral presentation like proposal defense or public interview should be very perfect and the anxiousness to make these perfect as perceived by them result in speaking anxiety. Some intensive English language students who experience public speaking anxiety sometimes suffer from low self-esteem. Apart from the foregoing emotional points relating to public speaking anxiety, physical symptoms relating to anxiety occur when students find himself or herself trembling, having cold clammy hands, having shaky voice, feeling heavy heartbeat, profusely sweating, feeling dizziness, having breathing discomfort to the extent of fading away what students already known or prepared to present or speak about. Occasionally, students having Social Phobia with respect to public speaking have the tendency of experiencing a panic attack.

Generally, Tobias (1986) defined anxiety to be a complex idea relying on one's feelings of self-efficacy as well as appraisals relating to the potential and perceived threats entrenched in particular situations, while Lader (1975) simply refers to anxiety to be often related to unpleasant feelings which is otherwise similar to fear. Anxiety in public speaking especially in language other than the first language such as English may cause students' minds to be weaker to the extent of affecting how they adapt to the environment they wish to belong to and their educational objectives. Similarly, Horwitz, \& Cope (1986, p.125) give a general definition of anxiety to be "the subjective feeling of tension, apprehension, nervousness, and worry associated with an arousal of the autonomic nervous system".

\subsection{Statement of the problem}

Anxiety is a state of uncomfortable emotion where danger is perceived, and the victim has a powerless feeling with the expression of tension in anticipation of danger. In the classification of anxiety, Scovel (1978) refer to 'trait anxiety' as a rapid permanent behavior or feeling to be anxious and this is considered to be part of personality. Spielberger (1983) refers to the second classification as 'state anxiety' which is explained to be apprehension encountered by the victim at a specific time period as a stimulus to a situation which is definite. Ellis (1994) refers to the third classification as 'situation-specific anxiety' which is associated with apprehension that stands out for particular phenomenon and situations. Gardner and MacIntyre (1994) explain the idea behind apprehension experienced as often related to a particular situation where the second language in which the speaker is not fully competent is to be used in public speaking.

For some years now researches have been directed towards public speaking anxiety. Public speaking anxiety is usually associated with fear among different categories of people in any society (Gibson, Gruner, Hanna, Smythe \& Hayes, 1980). In addition, "public speaking 
anxiety represents a cluster of evaluative feelings about speech making" (Daly, Vangelisti, Neel, \& Cavanaugh, 1989, p. 40) in which case speakers who are very anxious do not experience positive feelings related to the context of public speaking. For several years back, researchers in communication have tried to examine the explanation encompassing the psychological and physiological parts of public speaking anxiety in order to proffer considerable remedy that may lessen the adverse influence of anxiety for public speakers.

In the academics, especially among the scholars and researchers, the search for the factors responsible for public speaking anxiety has been a major caption of interest. Public speaking anxiety has constituted big challenges in academic environment and in all walks of life. This problem is always prominent and pronounces in speeches delivery, class oral presentation, group discussion and project defense. In recent time, the problem of public speaking anxiety has been on increase among the intensive English language international students of UUM. This phenomenon has constituted worry and challenge to the extent that urgent need is required to look into the factors contributing to this with a view to providing possible solution to overcome them.

Several studies have been conducted on public speaking anxiety from different perspectives. For example, some studies have linked the source of public speaking anxiety to insecurity or absence of self-confidence (Gutierrez-Calvo and Miguel-Tobal, 1998), lack of competence in public speaking (Behnke and Sawyer, 1999; Westenberg, 1999) and feeling of threat (Cano-Vindel and Miguel-Tobal, 1999; Lazarus and Folkman, 1986). Students' difference in speaking ability due to English language competence has also been linked to affect the ability to overcome nervousness that result in public speaking anxiety. Tasee (2009) found that students with lower perceived language ability are more anxious in speaking while Gregersen and Horwitz (2002) reported that competency in English language is one major influences of public speaking anxiety.

On the other hand, Pribyl, Keaten, \& Sakamoto (2001) noted that the degree of competency in English language bears no relationship with the public speaking anxiety. However, studies that have examined the influence of competence in English language on public speaking anxiety have been very few and their results are inconclusive. Due to the challenge it posed and its unresolved negative effect, it becomes imperative to have more studies in this area particularly among the international students of intensive English language in UUM with a view to providing possible remedies. Therefore, English language competency is a factor that is likely to influence public speaking anxiety among the intensive English language students of UUM. This in particular, takes into consideration of the international students in public speaking such as oral presentation or group discussion. Undoubtedly, some international students happen to have their first language to be English and there is tendency for them to be competent in speaking English publicly to the extent of not making them anxious.

\subsection{Literature Review}

Anxiety is often referred to as fearfulness, nervousness, emotional disturbance and intensity that human beings experience while communicating or dealing with their fellow human beings. This act affects the speaking proficiency of that particular person, attitudes and oral skill of an individual person, and has a weakening effect in communication (Horwitz et al, 1986; Ayu Rita and Nadhia Dalila 2008).Simply referred to as awful feelings, threaten situational condition and apprehension (Lader, 1975 and Tobias, 1986).Anxiety is defined as a feeling that is associated tension, apprehension, nervousness and worry, and also a state of vague fear, caused by an arousal of the autonomic nervous system, driving the human emotion through a very rough and unpalatable direction (Horwitz et al., 1986; Scovel, 1978). 


\subsection{Speaking Anxiety}

Speaking anxiety is a universally known fear characteristic of people giving speech to an audience. The phenomenon has been a focus of researchers for decades while it has similarly received the attention and interest of scholars of communication, psychology and education, with early researchers identifying the situation as stage fright with notably intense discomfort in the speaker (Lomas, 1944), associated with public speech or speaking. McCroskey (1977) suggest that demureness signifies fear in communicating to another person. Horwitz et al., (1986) pin point that, there are three attributes of speaking anxiety: adverse evaluation, test anxiety, non-confidence in expression as a result of shyness in communicating with other people. The negative evaluation makes an individual to rarely propose conversation and interact minimally (Gregersen \& Horwitz, 2002). These issues have attracted applied linguistics, Psychologists and English language educators (MacIntyre and Gardner, 1991). However, scholars viewed anxiety from two psychological angles (Levitt, 1980; Spielberger, 1983; Schwarzer, 1986). Globally, it is viewed perpetual trait and at a local level, it is viewed as a feedback to a particular situation of act (Brown 1994).

Researchers in the field of communication studied speaking anxiety as one facet of communication apprehension. At individual level it is a fear or anxiety linked with either real or expected communication with another person or group of persons (McCroskey, 1978), while others broaden their argument with references to their highly reputed investigations on physiological anxiety theories using various physiological indicators of speech anxiety, most especially in its peculiarity to speakers who are novices or neurotically timid among students of college level communication classes and many others settings (Sawyer and Behnke, 1991). According to McCroskey (1997) anxiety occurs in four different contexts: public speaking, groups, public meetings and Dyads. Eharman (1996) posited that anxiety is seen as part of human condition and he described it as an instinctively natural phenomenon that is extremely difficult to explain, especially its impact or effect on speaking proficiency in just a simple and exhaustible manner mainly, because it is traceable to many kinds of sources depending on the situation or a particular context that the individuals in question see its threat; most importantly, depending on their unique frame of reference.

\subsection{Public Speaking Anxiety}

Speaking before a group or public has been a long standing issue in the communication and language arena. Students tried to avoid speaking in public because of embarrassment, shaky voices, rapid heartbeat, feel discomfort, inferiority complex and low self-respect (Behnke et al., 1978; Clements \& Turpin, 1996). According to Krannich (2004) delivering speech, presentations in class and before public have been an important dilemma faced by students. Some researchers regard it as something peculiar to audience and public speaking context (Beatty et al., 1978), if possible shielding pubic communication (McCroskey\& Beatty, 1984); its consequence may vary across several processes or phases of speech preparation, delivery, and completion (Behnke\& Sawyer, 2001).

Public speaking anxiety is a dilemma faced by the populace, but students in particular. McCroskey (1977) reported that invariably twenty percent of students are faced with public speaking anxiety. To elucidate further, he documented that an individual level of fear of anxiety is correlated with either real or proposed communication with another individual or persons. In addition, North and Rives (2001) stated in their literature that individual with speaking anxiety most often experience different types of symptoms in a public speaking situation such as confusion, diarrhea, sweating, palpitations and also liable to gastrointestinal discomfort. Such risk of health related attacks linkable to speaking anxiety significantly 
brought health practitioners' interest to the discourse of this social phobia called Speaking Anxiety. Moreover, Tobia (1986) documented that anxiety has the potential to cause mental block in all the performances of the three human cognitive stages which are preoperational, concrete and formal operational stages. In an attempt to give more recognition to the phenomenon of Speaking Anxiety, it was revealed that when anxiety is viewed at a global level, it is a permanent trait, but when considered at a more local or situational level, anxiety can be experienced as a response to a particular situation or act; an arousal that is often linked with fear of failure, or worry due to performance evaluation (Brown, 1994; Tobia, 1986).

\subsection{Role of English language competence in influencing Public Speaking Anxiety}

English language competence simply refers to the ability to use appropriate communication pattern effectively in interaction (Bostiom 1984). It is evident from extant literature reviewed, however with early researches producing conflicting result in area of assessing the role of English language competency in the context of language achievement and speaking anxiety. Some literature revealed that there is positive relationship between English language competency and speaking with the argument that over-rated self-competence do unknowingly result in speech error, and consequently lead to unexpected anxiety, while other literature reported a negative relationship with a few others revealing neither positive nor negative relationships (Scovel, 1978).Intarapraset (2000) found a significant relationship between competency and speaking anxiety.

Khairi and NurulLina (2008) stated in their study conducted in Malaysia that with the trend of globalization and internationalization in which Malaysia is pursuing, the country will face more stiff competition from other foreign countries because most local students who do not enjoy speaking English language are now forced to compete with international students, among who are students with proficiency in English language, thus creating a problem of inter-relationship and communication between them. Therefore, such situation necessitates the need to regularly speak in English so that gradually some level of proficiency will be achieved. It is categorically stated as deduced from the study conducted that Malaysian local students do experience a high level of anxiety when discussing with their peers of other nationals who are better control of English, thus suggesting that English language competency moderates the extent of speaking anxiety in students.

Young (1992) and Wang (2010) stated that speaking in one's second language can cause high level of anxiety because the teacher often expect beginners to perform beyond their level of competence, as such force the student to break the silence before they are ready and use the language they have not yet subconsciously acquired. In this regard, learners will show poor speaking performance due to lack of the language competency, as some students are said to believe that one must not say anything in English until it is said correctly, thus probably avoid speaking most of the time. They both pointed out that the silence recorded from students during English lesson among high school students is not of their self-determined discipline or act, but because of the fear of negative evaluation from other people due to their self-assumed use of English language, and when they are unavoidably called to respond to a question or a situation, anxiety is conspicuous in their speech, class presentation and all other forms of public speaking scenario.

Maclntyre and Gardner (1991) in a research study that investigated the relationship between speaking anxiety and language learning highlighted the researchers' approach of adopting different perspectives: trait anxiety approach, state anxiety are the two principal approaches, 
while others employed situation specific measures, and concluded that it seems plausible to report that more meaningful and consistent results have emerged from the situation specific measure approach. Horwitz (2001) thus found consistent negative correlations between foreign language anxieties using the situation specific measures; especially the foreign language classroom anxiety scale and foreign language achievement supported the result. He further found that language anxiety was positively related to trait anxiety.

Liu and Jackson (2008) reported that language anxiety was positively correlated with unwillingness to communicate, but negatively correlated with language class risk-taking, and language class sociability. Significant amount of researches supported this idea and corroborated that belief is related to anxiety and language competency is the only controlling measure. It was also discovered in the study conducted by Gardner et al. (1997) that confident learners reported a low level of anxiety while less confident learners reported a high level of anxiety, with the explanation that confidence is borne out of their English language competency. McCroskey (1978), supplementing to the findings of previous studies, as discovered in his study reported that excessive anxiety is observed in people who have poor communication skill compared to those with sound communication skill. Carhill et al., (2008) identified that relationship between speaking anxiety and English language competence has been a subject of discourse among theorist. They found that low level of academic English language competency can obstruct full participation in academic context.

\subsection{Methodology and instrument}

The study adopts the quantitative approach with survey as the research method. The choice is informed by the fact that quantitative approach provides the researcher the opportunity to measure social phenomenon, like speaking anxiety, from a detached position and with minimal bias. Generalization of the outcome is also possible through careful and systematic selection of a representative sample through sampling procedure. Sampling is considered absolutely central to ensuring that the research project has external validity. By this, the findings of the study can be applied more widely beyond the particular project. This is possible because you have taken every precaution to make sure that the people you have surveyed, or the material you have selected to analyses, are representative of the group of people or the material you are primarily interested in. Given the objective of this study which is to determine the causes of speaking anxiety in relation to English language competence, the quantitative approach is considered the best approach.

\subsection{Statistical Technique}

Table (1) Results of Reliability Tests for Variables

\begin{tabular}{lllr}
\hline Variables & & N of Items \\
Cronbach's Alpha \\
Main Items
\end{tabular}

The table 1 above shows the reliability test of all variables for the main data. From the table, the scale's overall Cronbach's Alpha for all variables of the main data are greater than $70 \%$. In particular, the scale's overall Cronbach's Alpha for public speaking anxiety and English language competence are $86 \%$, and $79 \%$ respectively. Since these values of Cronbach's Alpha 
for these variables are greater than $70 \%$, it is concluded that these variables are reliable and consistent with the study's sample. Furthermore, the results indicate that items under each variable are consistent with the scores. This is because the Corrected Item-Total Correlation that determine the extent to which individual item relates with the overall score are all more than $30 \%$. The results obtained in the current study suggest that Corrected Item-Total Correlations are consistent for all of them are above $70 \%$ (See Appendix C).

Table (2) Correlation Result between ELC and Speaking Anxiety

\begin{tabular}{ll}
\hline $\begin{array}{l}\text { Dependent Variable } \\
\text { Independent variable }\end{array} \quad$ Speaking & \\
\hline Total & \\
English Language Competence (ELC)
\end{tabular}

\section{$-0.443 * * *$}

Pearson Correlation

0.000

Sig. (2-tailed)

108

No of Respondents

$* * *$ indicates that correlation is significant at the 0.01 level (2-tailed)

From the table above, the value of Pearson correlation is negative which implies that the total speaking anxiety as dependent variable move in the opposite direction with English language competence (dependent variable). The value of Pearson correlation is also shown to be 0.44 implying that there is mediumlevel of correlation between the two variables. Also, the results indicate that $r=0.44, n=108, p<0.05$. Since, $p=0.000$ in the result is smaller than $0.05 \%$ it implies that English language competence has significant impact on the total speaking anxiety. In order word, there is correlation between the two variables. Students with lower skills or competence in English language are affected by anxiety when speaking in public. Thus, the study hypothesis that English language competence has significant influence on public speaking anxiety is accepted.

\subsection{Result and Discussion}

Results of the correlation shows that English language competence has negative significant impact on the total speaking anxiety. The correlation between the two variables implies that students with lower skills or competence in English language are affected by anxiety when speaking in public. The results of the current study support those obtained in the previous studies by Carhill et al., (2008); Gregersen and Horwitz (2002); Horwitz (2001); Intarapraset (2000); Sawyer (1999); and Westenberg(1999). However, the results contradict those obtained in the past studies by Pribyl, Keaten, and Sakamoto (2001. To further support the outcome of correlation undertaken, the results of the speaking skills of the students of the intensive English language center were obtained. The overall results show that students who score below band 6.0 are 59 out of the total population of 112 which represents $52.68 \%$ and students who scored band 6.0 or above amounted to 53 representing $47.32 \%$ of the total students. This shows that the students who possessed skill or competence in English language were lower than other. 


\subsection{Conclusion}

The current results suggested that student with weak skills and who lacks competences in English language are more liable to entertain anxiety as compare to those who have good skills and competence in English language. Therefore, English language competence is one of the important factors determining the level of speaking anxiety among the students.

\section{References}

AvaryCarhill, CarolaSuárez-Orozco \& MarielaPáez (2008). Explaining English Language Proficiency among Adolescent Immigrant Students. American Educational Research Journal, 45(4), 1155-1179.

Behnke R.R. \& Sawyer C.R. (1999). Milestones of anticipatory public speaking anxiety, Communication Education, 48(2), 165-172.

Brown, H. D. (1994). Principles of language learning and teaching, (3rd Ed.). Englewood Cliffs,NJ: Prentice Hall.

Bostrum, R. N. (Ed.). (1984). Competence in communication. Beverly Hills, CA: Sage.

Cano-Vindel, A., \& Fernández Rodríguez, J. C. (1999). Perfiles de ira y ansiedad en el asma bronquial. Ansiedad y Estrés, 5(1), 25-35.

Clements, K., \& Turpin, G. (1996). Physiological effects of public speaking assessed using a measure of palmar sweating. Journal of Psychophysiology, 10, 283-290.

Daly, J. A., Vangelisti, A. L., Neel, H. L.,\& Cavanaugh, P. D. (1989). Pre performance concern associated with public speaking anxiety. Communication Quarterly, 37, 39-53.

Dolly Jesusita Young (1991). What Does Language Anxiety Research Suggest? The Modern Language Journal, 75(40), 426-439.

Eharman, M. (1996).Understanding second language learning difficulties. Thousand Oaks, CA: Sage.

Gardner, R. C., \&MacIntyre, P. D. (1994). The subtle effects of language anxiety on cognitive processing in the second language. Language Learning, 44, 283-305.

Gibson, J. W., Gruner, C. R., Hanna, M. S., Smythe, M. J., \& Hayes, M. T. (1980). The basic course in speech at U.S. colleges and universities: II Communication Education, 29, 1-9.

Gutiérrez-Calvo M. \& Miguel-Tobal J.J. (1998): "The anxiety response: concordance among components", Motivation and Emotion, 22, 211-230.

Gregersen, T., \&Horwitz, E. (2002). Language learning and perfectionism: Anxious and non-anxious language learners' reactions to their own oral performance. The Modern Language Journal, 86(4), 562-570.

Hamilton, C. (2008). Making Friends with your Public Speaking Anxiety Monster.A paper presented at the 2009 National Association of Communication Centers Mini-Conference.

Horwitz, E. K., Horwitz, M. B., \& Cope, J. (1986).Foreign language classroom anxiety. Modern Language Journal, 70, 125-132.

Intaraprasert, C. (2000). Language learning strategies employed by engineering students learning English at tertiary level in Thailand. Doctoral Dissertation, School of Education, the University of Leeds, UK.

Katz, L. (2000). Public Speaking Anxiety. Martin Counselling Center, University of Tennessee.

Lazarus R.S. \& Folkman S. (1986): Estrés y ProcesosCognitivos, Barcelona, Ediciones Martínez Roca.

Levitt, E. E. (1980). The psychology of anxiety. Hillsdale, NJ: Lawrence Erlbaum Associates.

MacIntyre, P. D., \& Gardner, R. C. (1991c). Investigating language class anxiety using the focused essay technique. Modern Language Journal, 75, 296-304. 
McCroskey, J. C. (1977). Oral communication apprehension: A summary of recent theory and research. Human Communication Research, 4, 78-96.

Meihua Liu \& Jane Jackson (2008).An Exploration of Chinese EFL Learners' Unwillingness to Communicate and Foreign Language Anxiety. The Modern Language Journal, 92(1), 71-86.

Pribyl, C.B., Keaten, J., \& Sakamoto, M. (2001). The effectiveness of a skills-based program in reducing public speaking anxiety. Japanese Psychological Research, 43, 148-155.

Scovel, T. (1978). The effect of effect on foreign language learning: A review of the anxiety research. Language Learning, 28, 129-42.

Spielberger, C. (1983). Manuel for the state-trait anxiety inventory.Palo Alto, Calif.: Consulting Psychologists Press. Spielberger, Charles D. \&Sarason, Irwin G. Stress and Anxiety, Volume I. New York: John Wiley \& Sons.

Schwarzer, R. (1986). Self-related cognition in anxiety and motivation: An introduction. In R. Schwarzer (Ed.), Self-related cognition in anxiety and motivation. Hillsdale, NJ: Erlbaum.

Tobias, S. (1986). Anxiety and cognitive processing of instruction. In R. Schwarzer (Ed.), Self- related cognition in anxiety and motivation (pp. 35-54). Hillsdale,NJ: Erlbaum.

Tasee, P. (2009). Factors affecting English major students' anxiety about speaking English. A thesis submitted in partial fulfilment of the requirement for the degree of Doctor of Philosophy in English Language Studies. Suranaree University of Technology.

Wang, T. (2010).Speaking Anxiety: More of a Function of Personality than Language Achievement.Chinese Journal of Applied Linguistics (Bimonthly), (33) 5.

Westenberg H.G.M. (1999): "Facing the challenge of social anxiety disorder", European Neuropsychofarmacology, 9(3), 93-99. 